\title{
Pyrogallol induces the death of human pulmonary fibroblast cells through ROS increase and GSH depletion
}

\author{
WOO HYUN PARK
}

\author{
Department of Physiology, Medical School, Research Institute for Endocrine Sciences, \\ Chonbuk National University, Jeonju 561-180, Republic of Korea
}

Received March 18, 2016; Accepted May 13, 2016

DOI: $10.3892 /$ ijo.2016.3543

\begin{abstract}
Pyrogallol (PG) inhibits the growth of various cells via stimulating $\mathrm{O}_{2}{ }^{--}$-mediated death. This study investigated the effects of PG on cell death in human pulmonary fibroblast (HPF) cells in relation to reactive oxygen species (ROS) and glutathione (GSH) levels. PG inhibited the growth of HPF cells with an $\mathrm{IC}_{50}$ of $\sim 50-100 \mu \mathrm{M}$ at $24 \mathrm{~h}$. PG induced a G1 phase arrest of the cell cycle and also triggered cell death accompanied by the loss of mitochondrial membrane potential (MMP; $\Delta \Psi_{\mathrm{m}}$ ), Bcl-2 decrease, p53 increase and the activation of caspase-3. PG increased $\mathrm{O}_{2}^{-{ }^{-}}$level in HPF cells and depleted GSH content in these cells. Z-VAD (a pan-caspase inhibitor) did not significantly change cell growth inhibition, death and MMP $\left(\Delta \Psi_{\mathrm{m}}\right)$ loss in PG-treated HPF cells. N-acetylcysteine (NAC) attenuated growth inhibition, death and MMP $\left(\Delta \Psi_{\mathrm{m}}\right)$ loss in PG-treated HPF cells and it decreased $\mathrm{O}_{2}{ }^{--}$level in these cells as well. However, L-buthionine sulfoximine (BSO) strongly increased ROS level in PG-treated HPF cells and it intensified growth inhibition, cell death, MMP $\left(\Delta \Psi_{\mathrm{m}}\right)$ loss and GSH depletion in these cells. In conclusion, PG-induced HPF cell death was closely related to increases in ROS level and GSH depletion.
\end{abstract}

\section{Introduction}

Pyrogallol (PG; benzene-1,2,3-triol) exists widely as a disintegration product of hydrolysable tannins and it possesses anti-psoriatic and anti-fungal properties (1). In addition, PG triggers mutagenesis, carcinogenesis and impairment of the

Correspondence to: Professor Woo Hyun Park, Department of Physiology, Medical School, Research Institute for Endocrine Sciences, Chonbuk National University, Jeonju 561-180, Republic of Korea E-mail: parkwh71@jbnu.ac.kr

Abbreviations: HPF, human pulmonary fibroblast; PG, pyrogallol; ROS, reactive oxygen species; MMP $(\Delta \Psi \mathrm{m})$, mitochondrial membrane potential; SOD, superoxide dismutase; CAT, catalase; GSH, glutathione; GPX, GSH peroxidase; TXN, thioredoxin; TXNR, TXN reductase; PI, propidium iodide; $\mathrm{H}_{2} \mathrm{DCFDA}, 2^{\prime}$, 7 '-dichlorodihydrofluorescein diacetate; DHE, dihydroethidium; CMFDA, 5-chloromethylfluorescein diacetate; NAC, N-acetylcysteine; BSO, L-buthionine sulfoximine

Key words: human pulmonary fibroblast, pyrogallol, cell death, reactive oxygen species, glutathione immune system (1). Since PG generates free radicals, especially superoxide anion $\left(\mathrm{O}_{2}{ }^{-}\right)$, it has been commonly utilized as a photographic developing agent and in hair dying industry (1). PG also has been employed to investigate the role of $\mathrm{O}_{2}{ }^{--}$in the biological system. PG induces the $\mathrm{O}_{2}{ }^{-}$-mediated death of various cell types such as cervical cancer cells (2), lymphoma cells (3), gastric cancer cells (4), reninoma cells (5) and lung cancer cells (6). Despite the beneficial effects of PG, its toxicity has been a main concern for the individuals exposed to it. The molecular mechanism to understand the toxicity of PG is still only partially understood.

The $\mathrm{O}_{2}{ }^{--}$belongs to the reactive oxygen species (ROS) with hydrogen peroxide $\left(\mathrm{H}_{2} \mathrm{O}_{2}\right)$ and hydroxyl radical $\left({ }^{\circ} \mathrm{OH}\right)$. ROS are involved in a variety of cellular events such as gene expression, differentiation, cell proliferation and cell death $(7,8)$. They are primarily generated during the mitochondrial respiration and are specifically made by various oxidases such as nicotinamide adenine dinucleotide phosphate (NADPH) oxidase and xanthine oxidase (XO) (9). In relation to the principal metabolic pathways, superoxide dismutases (SODs) converts $\mathrm{O}_{2}{ }^{--}$to $\mathrm{H}_{2} \mathrm{O}_{2}$ (10). Further metabolism yields $\mathrm{O}_{2}$ and $\mathrm{H}_{2} \mathrm{O}$ through catalase (CAT) or glutathione (GSH) peroxidase (GPX) (11). Especially, thioredoxin (TXN) system consists of TXN, TXN reductase (TXNR) and NADPH, which is critically implicated in maintaining cellular redox homeostasis (12). TXN as a thiol reductase is a potent anti-oxidant and acts as a scavenger of ROS (12). Oxidative stress due to the overproduction of ROS and/or the accumulation of them can initiate events that lead to cell death via the oxidation of DNA, lipid and protein.

PG reduces the growth of Calu-6 and A549 lung cancer cells via apoptosis and cell cycle arrest (13-15). PG also induces GSH depletion in lung cancer cells $(6,13)$. However, little is known about the cellular effects of PG on normal primary lung cells. Therefore, this study investigated the effects of PG on cell growth and death in human pulmonary fibroblast (HPF) cells in relation to ROS and GSH levels, and examined the effects of $\mathrm{N}$-acetylcysteine (NAC) and vitamin $\mathrm{C}$ (well known antioxidants) or L-buthionine sulfoximine (BSO; an inhibitor of GSH synthesis) on PG-induced HPF cell death.

\section{Materials and methods}

Cell culture. HPF cells purchased from PromoCell GmbH (Heidelberg, Germany) were cultured in RPMI-1640 supple- 
mented with $10 \%$ fetal bovine serum (Sigma-Aldrich Chemical Co., St. Louis, MO, USA) and $1 \%$ penicillin-streptomycin (Gibco BRL, Grand Island, NY, USA). The cells between passages four and eight were utilized for the experiments.

Reagents. PG was purchased from Sigma-Aldrich Chemical Co. and it was dissolved in water. Pan-caspase inhibitor (Z-VAD-FMK; benzyloxycarbonyl-Val-Ala-Asp-fluoromethylketone) was obtained from R\&D Systems, Inc. (Minneapolis, $\mathrm{MN}, \mathrm{USA}$ ). NAC and BSO were obtained from Sigma-Aldrich Chemical Co. NAC was dissolved in the buffer $[20 \mathrm{mM}$ HEPES (pH 7.0)]. BSO was dissolved in water. Vitamin C purchased from Riedel-de Haen (Hannover, Germany) was also dissolved in water. Based on a previous study (16), cells were pretreated with or without $15 \mu \mathrm{M}$ Z-VAD, 2 mM NAC, $10 \mu \mathrm{M}$ BSO or $0.4 \mathrm{mM}$ vitamin $\mathrm{C}$ for one hour prior to the treatment of PG.

Cell growth inhibition assays. Cell growth changes were determined by measuring the 3-(4,5-dimethylthiazol-2-yl)2,5-diphenyltetrazolium bromide (MTT, Sigma-Aldrich Chemical Co.) dye absorbance as previously described (17). Cells were exposed to the indicated amounts of PG (5-200 $\mu \mathrm{M})$ with or without Z-VAD, NAC, vitamin C or BSO for $24 \mathrm{~h}$.

Cell cycle and sub-G1 analysis. Cell cycle and sub-G1 cells were determined by propidium iodide (PI, Ex/Em=488/617 nm; Sigma-Aldrich) staining as previously described (13). Cells were incubated with the indicated amounts of PG (5-100 $\mu \mathrm{M})$ for $24 \mathrm{~h}$. Cellular DNA content was measured using a FACStar flow cytometer (Becton-Dickinson, Franklin Lakes, NJ, USA).

Annexin V/PI staining for cell death detection. Apoptosis was determined by staining cells with Annexin V-fluorescein isothiocyanate (FITC, Ex/Em=488/519 nm; Invitrogen Molecular Probes, Eugene, OR, USA) and propidium iodide (PI, Ex/Em=488/617 nm; Sigma-Aldrich) as previously described (18). Cells were incubated with the indicated amounts of PG $(5-100 \mu \mathrm{M})$ in the presence or absence of Z-VAD, NAC, vitamin C or BSO for $24 \mathrm{~h}$. Annexin V/PI staining was analyzed with a FACStar flow cytometer (Becton-Dickinson).

Western blot analysis. The changes of proteins related to apoptosis and antioxidant system were determined by western blotting as previously described (18). Cells were incubated with $100 \mu \mathrm{M}$ PG for $24 \mathrm{~h}$. Samples containing $10 \mu \mathrm{g}$ total protein were resolved by $12.5 \%$ SDS-PAGE gels. The antibodies against Bcl-2, Bax, p53, procaspase-3, CAT, SOD1, TXN, TXNR1 and $\beta$-actin were obtained from Santa Cruz Biotechnology (Santa Cruz, CA, USA).

Measurement of MMP $\left(\Delta \Psi_{m}\right) \cdot \operatorname{MMP}\left(\Delta \Psi_{m}\right)$ levels were measured using a rhodamine 123 fluorescent dye (Sigma-Aldrich; $\mathrm{Ex} / \mathrm{Em}=485 / 535 \mathrm{~nm})$ as previously described $(17,18)$. Cells were incubated with the indicated amounts of PG (5-100 $\mu \mathrm{M})$ in the presence or absence of Z-VAD, NAC, vitamin C or BSO for $24 \mathrm{~h}$. The absence of rhodamine 123 from cells indicated the loss of MMP $\left(\Delta \Psi_{\mathrm{m}}\right)$ in HPF cells. The MMP $\left(\Delta \Psi_{\mathrm{m}}\right)$ levels in the cells excluding MMP $\left(\Delta \Psi_{\mathrm{m}}\right)$ loss cells were expressed as mean fluorescence intensity (MFI), which was calculated by CellQuest software (Becton-Dickinson).

Quantification of caspase-3 and caspase- 8 activities. The activities of caspase- 3 and -8 were assessed using the caspase- 3 and -8 colorimetric Assay kits (R\&D Systems, Inc.). Cells were incubated with $100 \mu \mathrm{M}$ PG for $24 \mathrm{~h}$. The activities of caspase- 3 and -8 were expressed in arbitrary absorbance units, as previously described (18).

Detection of intracellular ROS levels. Intracellular ROS were detected by a fluorescent probe dye, 2',7'-dichlorodihydrofluorescein diacetate $\left(\mathrm{H}_{2} \mathrm{DCFDA}, \mathrm{Ex} / \mathrm{Em}=495 / 529 \mathrm{~nm}\right.$; Invitrogen Molecular Probes) as previously described (18). Dihydroethidium (DHE, Ex/Em=518/605 nm; Invitrogen Molecular Probes) is a fluorogenic probe that is highly selective for $\mathrm{O}_{2}{ }^{--}$among ROS. Mitochondrial $\mathrm{O}_{2}{ }^{-}$level was detected using MitoSOX ${ }^{\mathrm{TM}}$ Red mitochondrial $\mathrm{O}_{2}{ }^{*}$ indicator $(\mathrm{Ex} / \mathrm{Em}=510 / 580 \mathrm{~nm}$; Invitrogen Molecular Probes) as previously described (19). Cells were incubated with the indicated doses of PG (5-100 $\mu \mathrm{M})$ in the presence or absence of NAC, BSO or vitamin C for the indicated times. DCF, DHE and MitoSOX Red fluorescences were detected using a FACStar flow cytometer (Becton-Dickinson). ROS levels were expressed as mean fluorescence intensity.

Detection of the intracellular glutathione (GSH). Cellular GSH levels were analyzed using a 5-chloromethylfluorescein diacetate dye (CMFDA, Ex/Em=522/595 nm; Invitrogen Molecular Probes) as previously described $(17,18)$. Cells were incubated with the indicated doses of PG $(5-100 \mu \mathrm{M})$ in the presence or absence of NAC, BSO or vitamin C for the indicated times. CMF fluorescence intensity was determined using a FACStar flow cytometer (Becton-Dickinson). Negative CMF staining (GSH depleted) cells were expressed as the percent of (-) CMF cells.

Statistical analysis. The data were analyzed using Instat software (GraphPad Prism4, San Diego, CA, USA). The Student's $\mathrm{t}$-test or one-way analysis of variance (ANOVA) with post hoc analysis using Tukey's multiple comparison test was used for parametric data. Statistical significance was defined as $\mathrm{p}<0.05$.

\section{Results}

Effects of PG on cell growth and cell cycle distributions in HPF cells. Based on MTT assays, PG dose-dependently decreased $\mathrm{HPF}$ cell growth with an $\mathrm{IC}_{50}$ of $\sim 50-100 \mu \mathrm{M}$ at $24 \mathrm{~h}$ (Fig. 1A). When cell cycle distributions were investigated in PG-treated HPF cells, $5 \mu \mathrm{M}$ PG seemed to induce a G1 phase arrest of the cell cycle as compared with control cells and the higher doses of 50 or $100 \mu \mathrm{M}$ PG strongly increased the proportion of G1 phase (Fig. 1B). However, an increase in sub-G1 DNA content cells was not observed in PG-treated HPF cells (Fig. 1B).

Effects of PG on cell death, apoptosis-related proteins and $\operatorname{MMP}\left(\Delta \Psi_{m}\right)$ in HPF cells. As shown in Fig. 2A, PG increased the numbers of Annexin V-FITC positive cells in a dosedependent manner. Concerning the relationship between $\mathrm{Bcl}-2$ and Bax regulation in PG-treated HPF cells, both proteins were 
A

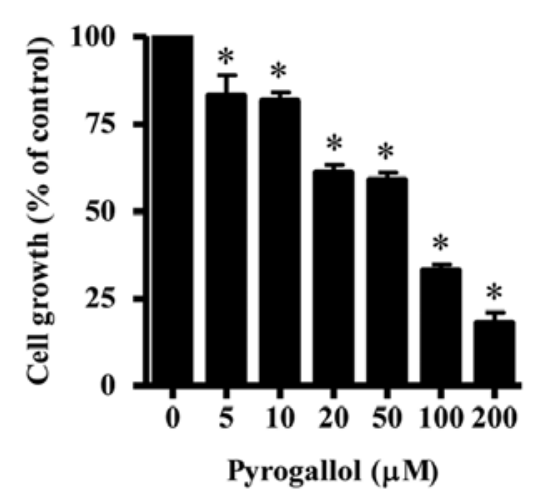

B
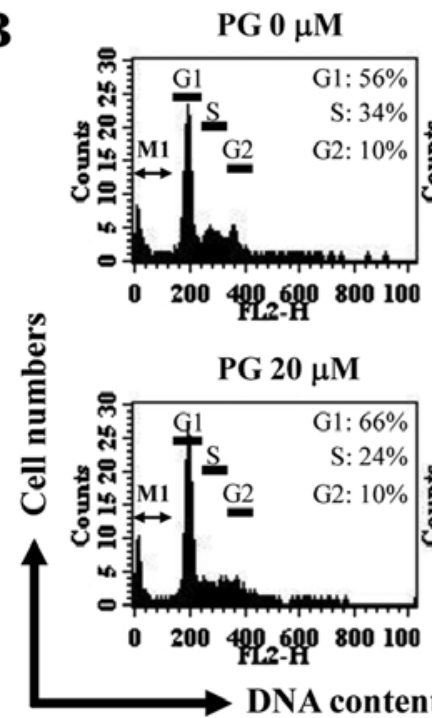
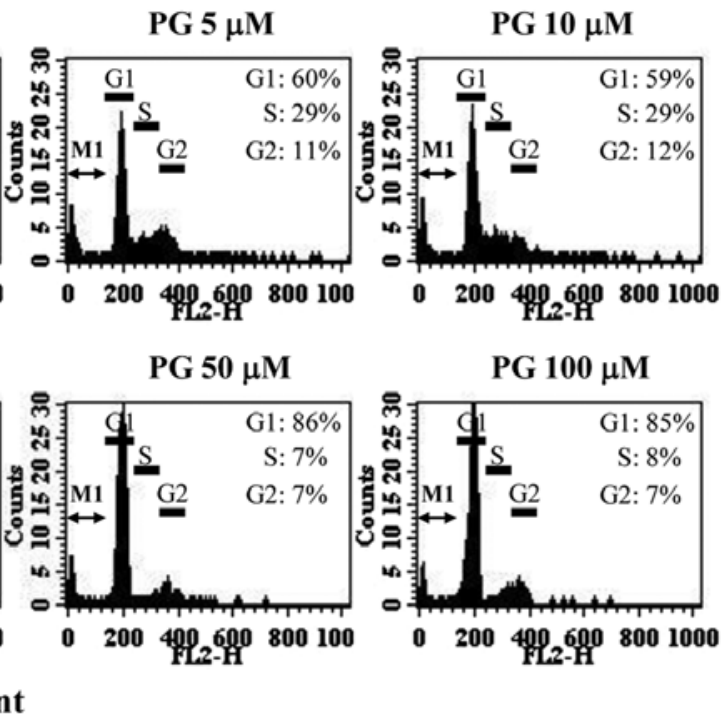

Figure 1. Effects of PG on cell growth and cell cycle distributions in HPF cells. (A) The graph shows cellular growth changes. (B) Each histogram shows the cell cycle distributions. M1 indicates sub-G1 cells in each histogram. " $\mathrm{p}<0.05$ compared with the control group.

A

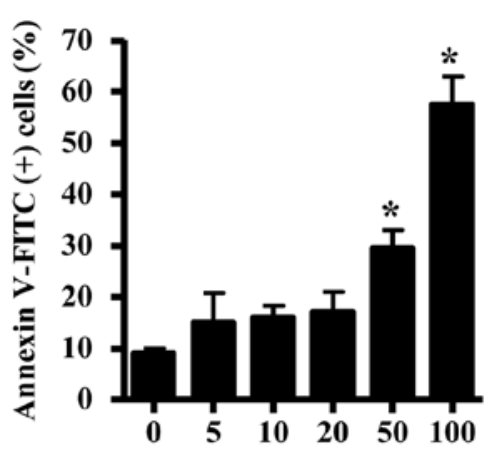

Pyrogallol $(\mu \mathrm{M})$

D

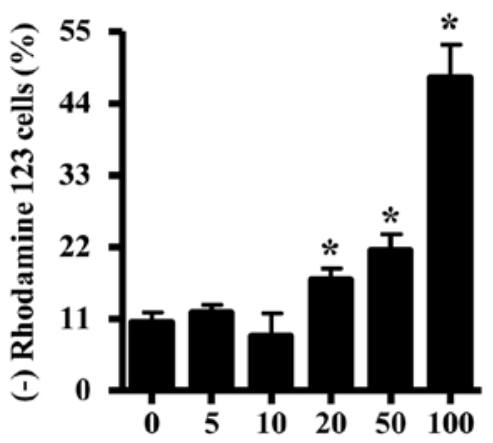

Pyrogallol $(\mu \mathrm{M})$
B

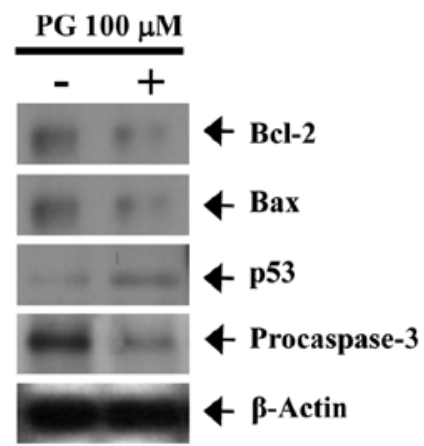

$\mathbf{E}$

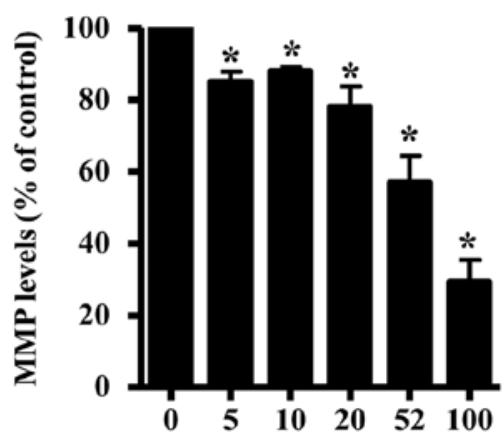

Pyrogallol $(\mu \mathrm{M})$
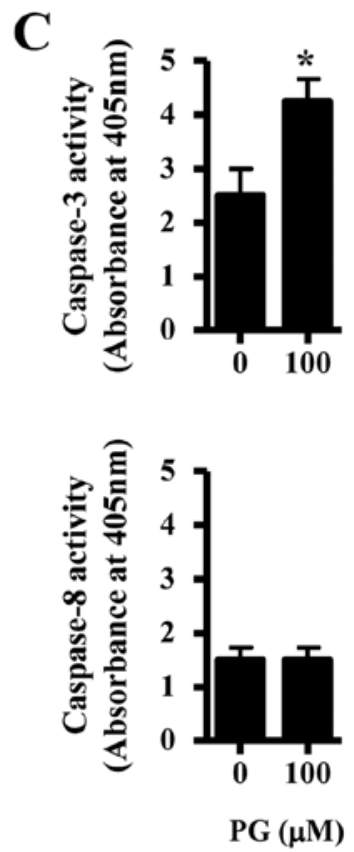

PG $(\mu \mathrm{M})$

Figure 2. Effects of PG on cell death and MMP $\left(\Delta \Psi_{\mathrm{m}}\right)$ in HPF cells. (A) The graph shows the percents of Annexin V-FITC cells. (B) The figure shows the levels of Bcl-2, Bax, p53, caspase-3 and $\beta$-actin. (C) The graphs show the activities of caspase-3 and caspase-8 in HPF cells. (D and E) Graphs show the percents of rhodamine 123-negative [MMP $\left(\Delta \Psi_{\mathrm{m}}\right)$ loss] cells (D) and MMP $\left(\Delta \Psi_{\mathrm{m}}\right)$ levels in the cells exclusive of MMP $\left(\Delta \Psi_{\mathrm{m}}\right)$ loss cells (E). "p $<0.05$ compared with the control group.

clearly decreased by PG (Fig. 2B). p53, which regulates the expression of Bcl-2, Bax or cyclin-dependent kinase inhibitor (CDKI) in response to DNA damage (20), was increased by PG (Fig. 2B). Caspase-3 plays an essential role as an executor in apoptosis (21). A 32-kDa precursor (procaspase-3) obviously disappeared in PG-treated HPF cells (Fig. 2B) and the activity of caspase-3 was increased by PG (Fig. 2C). However, the activity of caspase- 8 , which is involved in receptor- or 

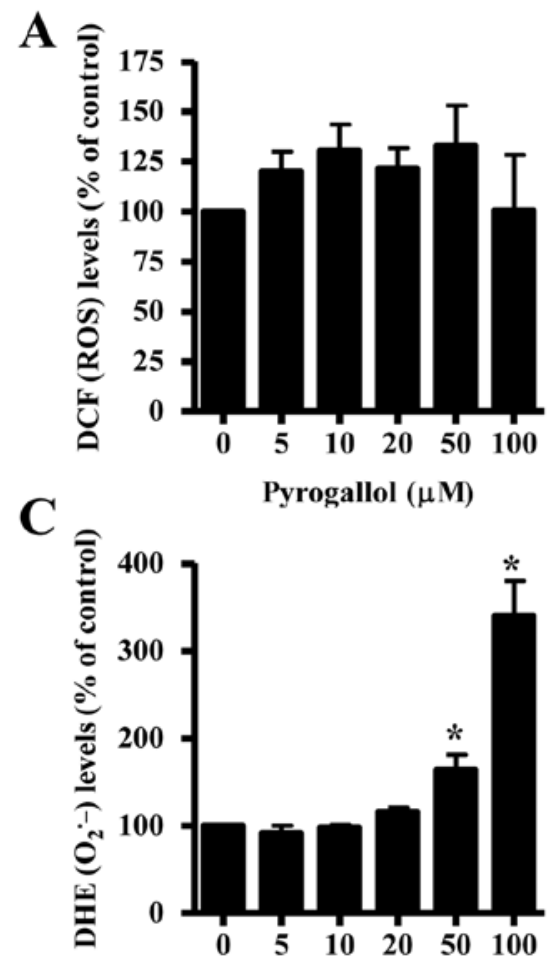

F

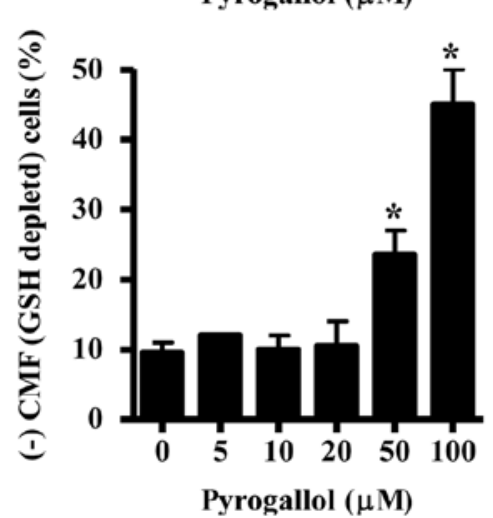

B

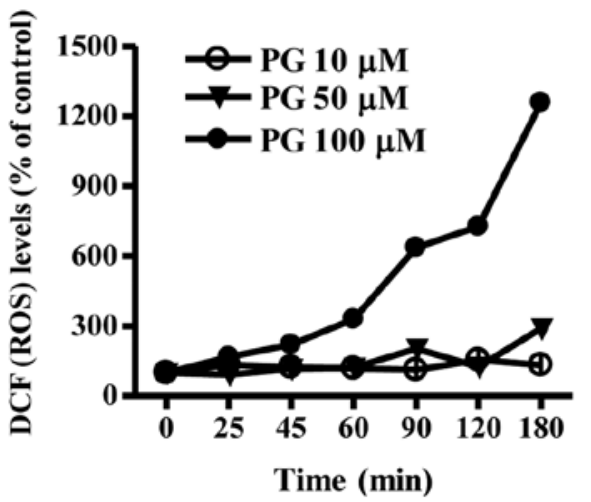

D

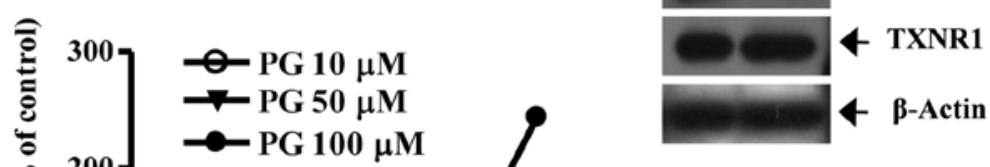

E

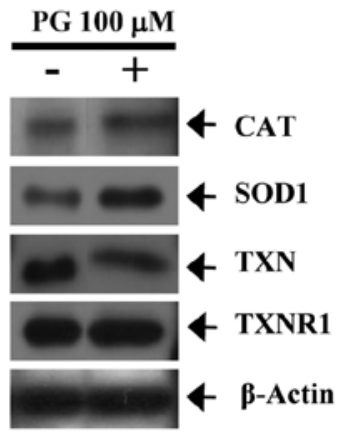

G

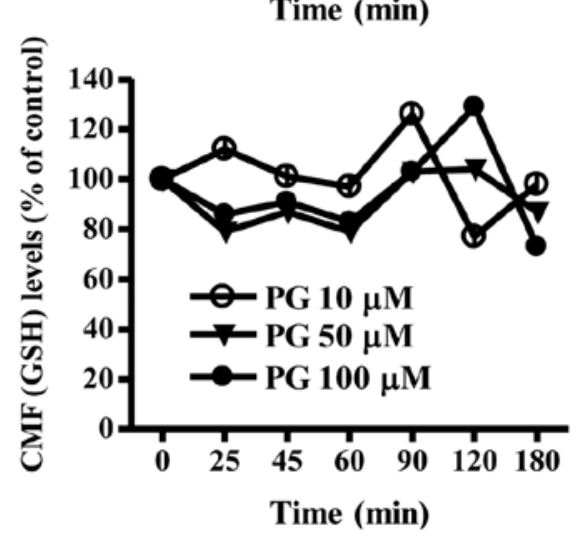

Figure 3. Effects of PG on ROS and GSH levels in HPF cells. (A and B) Graphs indicate DCF (ROS) levels (\%) at 24 h (A) and the early times (B). $\left(\mathrm{C}\right.$ and D) Graphs indicate DHE $\left(\mathrm{O}_{2}^{\circ}\right)$ levels $(\%)$ at $24 \mathrm{~h}(\mathrm{C})$ and the early times (D). (E) The figure shows the levels of CAT, SOD1, TXN, TXNR1 and $\beta$-actin. (F and G) Graphs show (-) CMF (GSH-depleted) cells (\%) at $24 \mathrm{~h}(\mathrm{~F})$ and GSH levels at the early times (G). " p $<0.05$ compared with the control group.

extrinsic-mediated apoptosis (22), was not affected by PG (Fig. 2C). In addition, 20-100 $\mu \mathrm{M}$ PG significantly induced the loss of MMP $\left(\Delta \Psi_{\mathrm{m}}\right)$ in HPF cells (Fig. 2D). The levels of MMP $\left(\Delta \Psi_{\mathrm{m}}\right)$ in HPF cells except for MMP $\left(\Delta \Psi_{\mathrm{m}}\right)$ loss cells were decreased by PG in a dose-dependent manner (Fig. 2E).

Effects of PG on ROS, GSH and antioxidant-protein levels in HPF cells. As shown in Fig. 3A, 5-50 $\mu \mathrm{M}$ PG increased ROS (DCF) levels in HPF cells at $24 \mathrm{~h}$ but $100 \mu \mathrm{M}$ PG did not significantly affect the level. While 10 and $50 \mu \mathrm{M}$ PG did not alter ROS (DCF) levels from 25 to $120 \mathrm{~min}, 50 \mu \mathrm{M}$ PG increased the level at $180 \mathrm{~min}$ (Fig. 3B). Treatment with $100 \mu \mathrm{M}$ PG augmented ROS (DCF) levels from the early time of $25 \mathrm{~min}$ and the gradual increases continued for the tested times (25-180 min) (Fig. 3B). Intracellular $\mathrm{O}_{2}{ }^{--}$(DHE) level significantly increased in 50 or $100 \mu \mathrm{M}$ PG-treated HPF cells whereas the level was not clearly changed by $5-20 \mu \mathrm{M}$ PG treat-

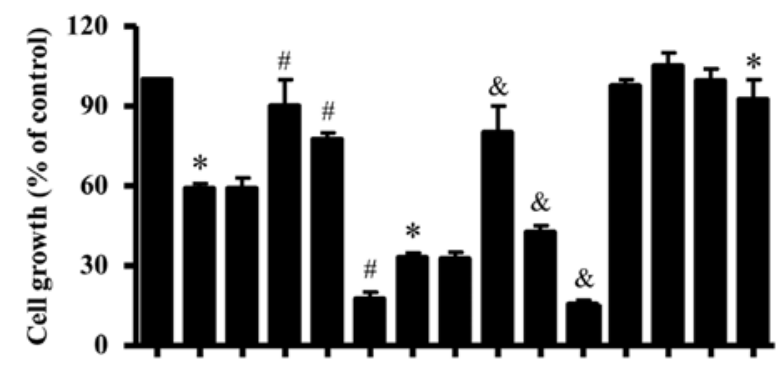

Pyrogallol $\mu \mathrm{M}$ : - $5050505050100100100100100-5$ Z-VAD $15 \mu \mathrm{M}:-\quad-\quad+\quad-\quad-\quad-+-\quad-\quad+\quad-\quad-$

NAC $2 \mathrm{mM}:-\quad-\quad+-\quad-\quad-++--+$ Vitamin C $0.4 \mathrm{mM}:-c_{-}-+\quad-\quad-\quad-\quad+--\quad+$

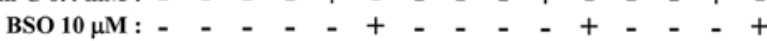

Figure 4. Effects of Z-VAD, NAC, vitamin C or BSO on cell growth in PG-treated HPF cells. The graph shows cell growth changes. ${ }^{*} \mathrm{p}<0.05$ compared with the control group. ${ }^{\#} \mathrm{p}<0.05$ compared with cells treated with $50 \mu \mathrm{M}$ PG. ${ }^{\circledR} \mathrm{p}<0.05$ compared with cells treated with $100 \mu \mathrm{M}$ PG. 
A

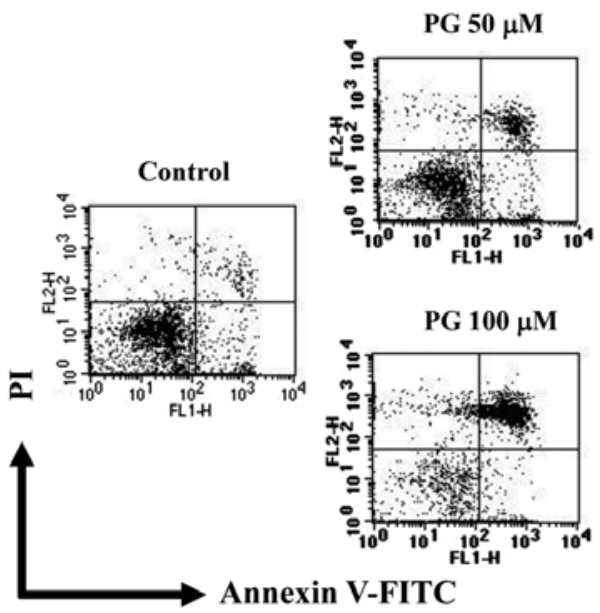

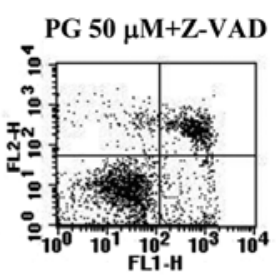
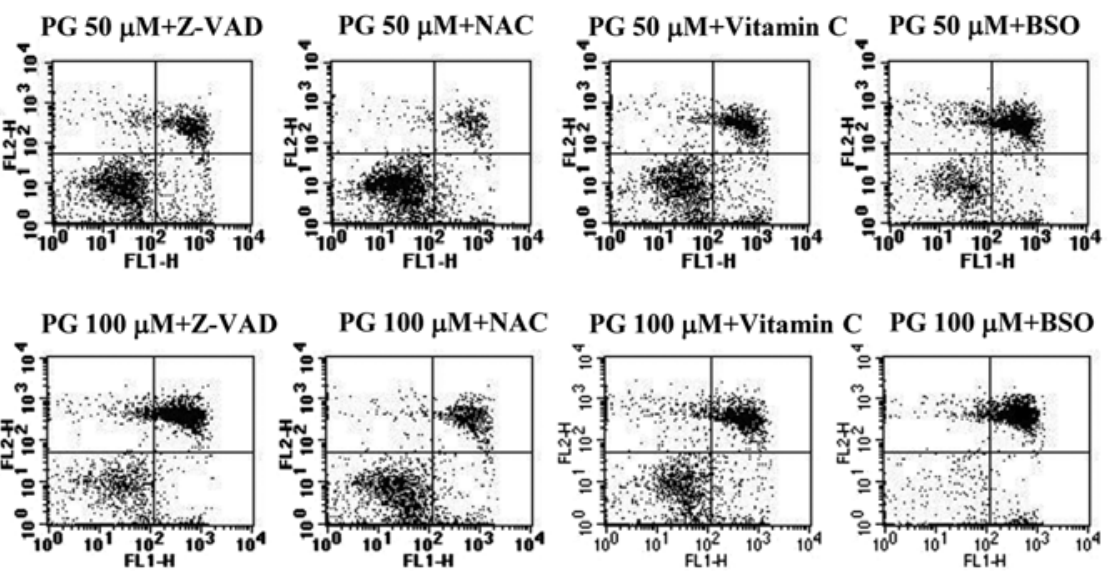

B

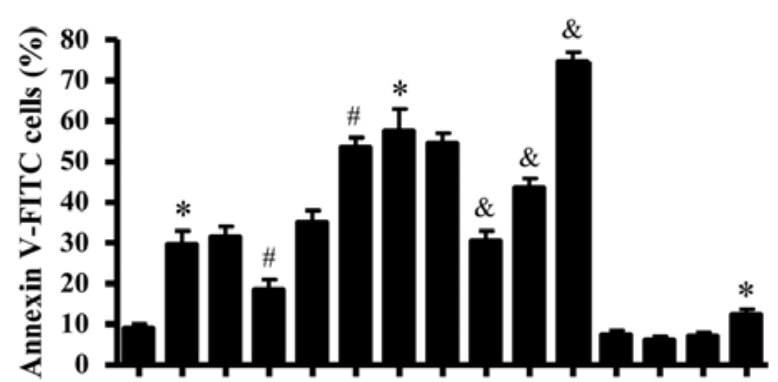

C

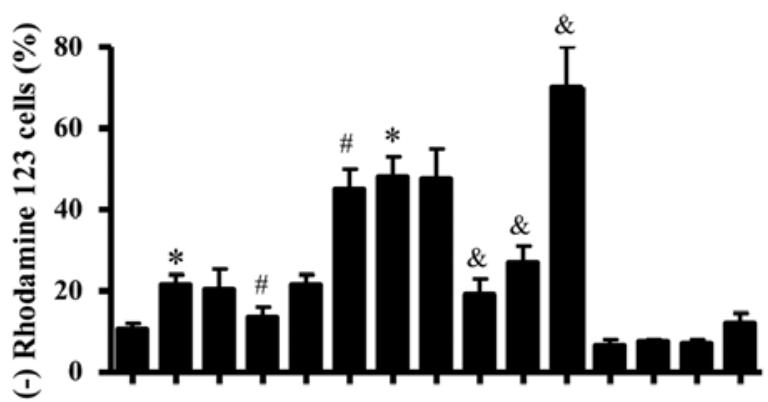

$\begin{array}{llllllllllllll}- & 50 & 50 & 50 & 50 & 50 & 100 & 100 & 100 & 100 & 100 & - & - & -\end{array}$

$-\quad+\quad-\quad-\quad-+\quad-\quad-\quad+\quad-\quad-$

$-\quad-\quad+-\quad-\quad-\quad+\quad-\quad-\quad+\quad-$

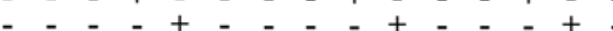

- $-\quad-\quad+\quad-\quad-+\ldots-$ -

Figure 5. Effects of Z-VAD, NAC, vitamin C or BSO on cell death and MMP $\left(\Delta \Psi_{\mathrm{m}}\right)$ in PG-treated HPF cells. (A) Each figure shows Annexin V-FITC/PI cells. (B and C) Graphs show the percents of Annexin V-positive staining cells from A (B) and rhodamine 123 -negative [MMP $\left(\Delta \Psi_{\mathrm{m}}\right)$ loss] cells $(\mathrm{C})$. $^{*} \mathrm{p}<0.05$ compared with the control group. ${ }^{\#} \mathrm{p}<0.05$ compared with cells treated with $50 \mu \mathrm{M}$ PG. ${ }^{\&} \mathrm{p}<0.05$ compared with cells treated with $100 \mu \mathrm{M}$ PG.

ment (Fig. 3C). While 10 or $50 \mu \mathrm{M}$ PG transiently decreased $\mathrm{O}_{2}{ }^{-}$level in $\mathrm{HPF}$ cells at $25 \mathrm{~min}, 100 \mu \mathrm{M}$ PG increased the level at this time (Fig. 3D). At $180 \mathrm{~min}$, all the tested doses of PG increased $\mathrm{O}_{2}{ }^{--}$levels in HPF cells and $100 \mu \mathrm{M}$ PG showed a strong effect on the level (Fig. 3D). When antioxidant-protein levels were assessed in $100 \mu \mathrm{M}$ PG-treated HPF cells, the expression of CAT and SOD1 was increased by PG treatment (Fig. 3E). In addition, PG clearly downregulated the expression of TXN in HPF cells and did not change that of TXNR1 (Fig. 3E).

In relation to GSH levels, 50 or $100 \mu \mathrm{M}$ PG significantly increased GSH depleted cell number in HPF cells whereas lower doses of 5, 10 or $20 \mu \mathrm{M}$ PG did not induce GSH depletion in HPF cells, as compared with control HPF cells (Fig. 3F). At the early time of $25 \mathrm{~min}$ in PG-treated HPF cells, $10 \mu \mathrm{M}$ PG transiently increased GSH level whereas 50 or $100 \mu \mathrm{M}$ PG decreased the level (Fig. 3G). Although there were transient increases in GSH levels at 90 or 120 min in PG treated-HPF cells, the GSH levels generally decreased in these cells at 180 min (Fig. 3G).

Effects of Z-VAD, NAC, vitamin C or BSO on cell growth, cell death and MMP $\left(\Delta \Psi_{m}\right)$ in PG-treated HPF cells. For this experiment, 50 or $100 \mu \mathrm{M}$ PG was used as a suitable dose to differentiate the levels of cell growth inhibition and death. Treatment with $15 \mu \mathrm{M}$ Z-VAD did not significantly affect growth inhibition in PG-treated or -untreated HPF cells (Fig. 4). Both antioxidants of NAC and vitamin C significantly prevented the growth inhibition by 50 or $100 \mu \mathrm{M}$ PG whereas BSO enhanced the growth inhibition (Fig. 4). BSO alone slightly inhibited HPF cell growth (Fig. 4). In relation to cell death, Z-VAD did not influence HPF cell death by PG. However, NAC significantly rescued HPF cells from the insult of PG (Fig. 5A and B). While vitamin C did not attenuate cell death in $50 \mu \mathrm{M}$ PG-treated HPF cells, this agent significantly prevented the death induced by $100 \mu \mathrm{M}$ PG (Fig. 5A and B). BSO enhanced HPF cell death by PG (Fig. 5A and B). Similar to the results of Annexin $\mathrm{V}$ staining cells, Z-VAD did not change the loss of MMP $\left(\Delta \Psi_{\mathrm{m}}\right)$ in PG-treated HPF cells and NAC decreased the loss in these cells (Fig. 5C). In addition, vitamin C significantly prevented the loss of MMP $\left(\Delta \Psi_{\mathrm{m}}\right)$ induced by $100 \mu \mathrm{M}$ PG (Fig. 5C). BSO enhanced MMP $\left(\Delta \Psi_{\mathrm{m}}\right)$ loss in PG-treated HPF cells (Fig. 5C).

Effects of Z-VAD, NAC, vitamin C or BSO on ROS and GSH levels in PG-treated HPF cells. As shown in Fig. 6A, ROS 
A

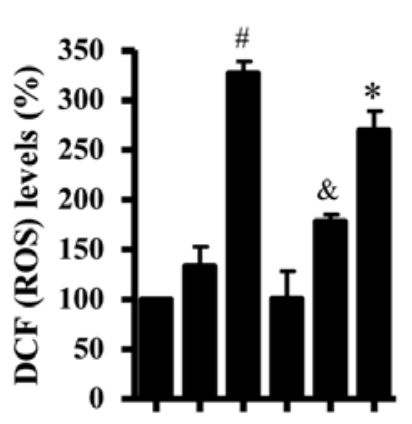

Pyrogallol $\mu \mathrm{M}$ ： - 5050100100 -

Z-VAD $15 \mu \mathrm{M}$ : - $-{ }_{-}-{ }_{-}$

NAC $2 \mathrm{mM}:-{ }_{-}-{ }_{-}$

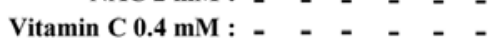

BSO $10 \mu \mathrm{M}:-{ }_{-}++$

C

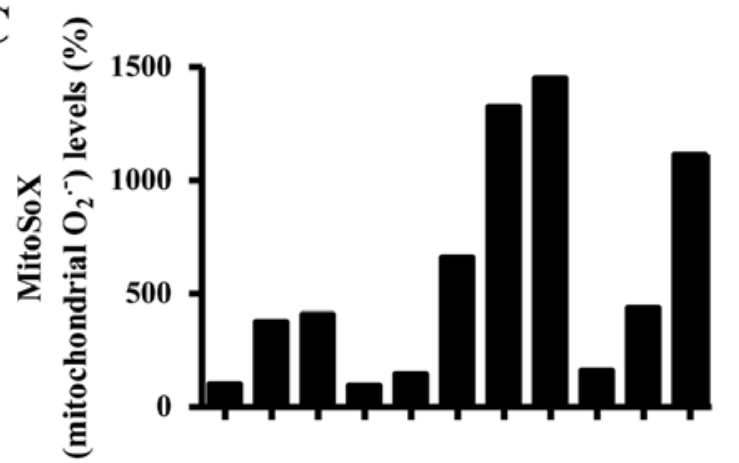

Pyrogallol $\mu \mathrm{M}$ : - $\begin{array}{cccccccccc}50 & 50 & 50 & 50 & 50 & 100 & 100 & 100 & 100 & 100\end{array}$

Z-VAD $15 \mu \mathrm{M}:-\quad-\quad+\quad-\quad-\quad-+\quad-\quad-$

NAC $2 \mathrm{mM}:-{ }_{-} \quad+\quad-\quad-\quad-\quad+\quad-$

Vitamin C $0.4 \mathrm{mM}$ : - $\quad-\quad-\quad-\quad+\quad-\quad-\quad-\quad-\quad+$

BSO $10 \mu \mathrm{M}$ : - $\quad-\quad-\quad+\quad-\quad-\quad+$

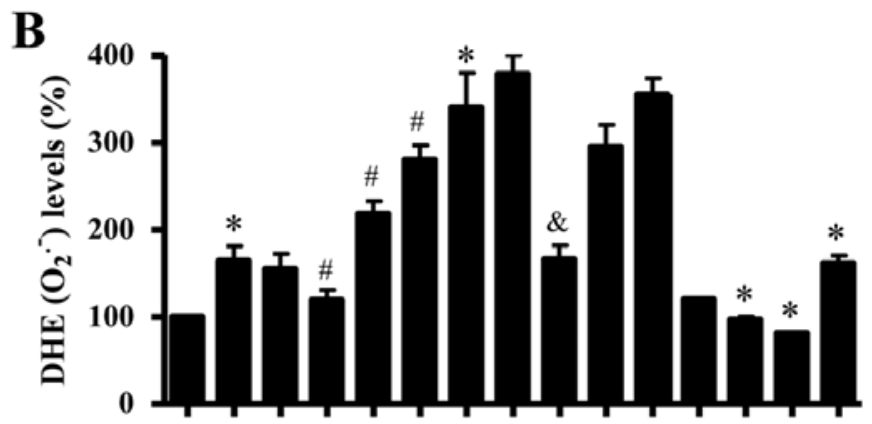

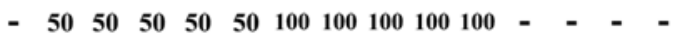

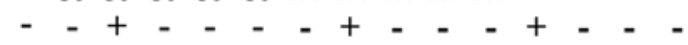

$-\quad-+\ldots-c_{-}+--_{-}+-$

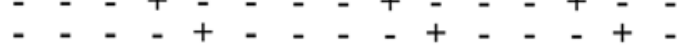

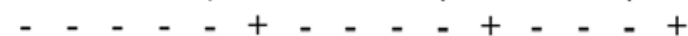

D

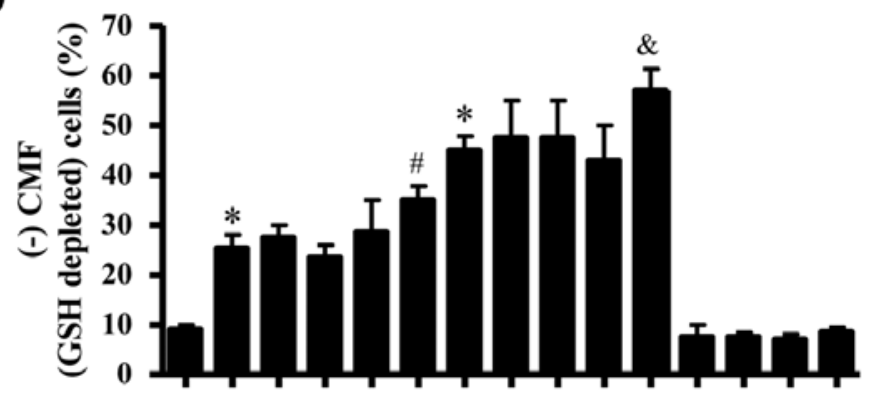

$\begin{array}{lllllllllllllll}- & 50 & 50 & 50 & 50 & 50 & 100 & 100 & 100 & 100 & 100 & - & - & - & - \\ - & - & + & - & - & - & - & + & - & - & - & + & - & - & - \\ - & - & - & + & - & - & - & - & + & - & - & - & + & - & - \\ - & - & - & - & + & - & - & - & - & + & - & - & - & + & - \\ - & - & - & - & - & + & - & - & - & - & + & - & - & - & +\end{array}$

Figure 6. Effects of Z-VAD, NAC, vitamin C or BSO on ROS and GSH levels in PG-treated HPF cells. (A-C) Graphs indicate ROS (as determined by DCF) levels (\%) (A), DHE $\left(\mathrm{O}_{2}^{*}\right)$ levels (\%) (B) and mitoSOX (mitochondrial $\mathrm{O}_{2}^{*}$ ) levels (\%) compared with control cells (C). (D) Graph shows (-) CMF (GSH-depleted) cells (\%). ${ }^{*} \mathrm{p}<0.05$ compared with the control group. ${ }^{\#} \mathrm{p}<0.05$ compared with cells treated with $50 \mu \mathrm{M} \mathrm{PG}$. ${ }^{\star} \mathrm{p}<0.05$ compared with cells treated with $100 \mu \mathrm{M}$ PG.

(DCF) levels in PG-treated or -untreated HPF cells were significantly increased by BSO. However, Z-VAD, NAC or vitamin $\mathrm{C}$ did not strongly change ROS (DCF) levels in PG-treated HPF cells (data not shown). Z-VAD also did not significantly affect $\mathrm{O}_{2}^{--}$level in PG-treated HPF cells whereas NAC strongly decreased $\mathrm{O}_{2}^{-}$level in these cells (Fig. 6B). While vitamin $\mathrm{C}$ increased $\mathrm{O}_{2}{ }^{-}$level in $50 \mu \mathrm{M}$ PG-treated HPF cells, it decreased the level in $100 \mu \mathrm{M}$ PG-treated cells (Fig. 6B). Both NAC and vitamin $\mathrm{C}$ decreased basal ROS levels including $\mathrm{O}_{2}{ }^{-}$in HPF control cells (Fig. 6B). In contrast, BSO significantly increased $\mathrm{O}_{2}^{-{ }^{-}}$levels in $50 \mu \mathrm{M}$ PG-treated or -untreated HPF cells but it slightly increased the level in $100 \mu$ M PG-treated cells (Fig. 6B). Furthermore, MitoSOX Red fluorescence levels strongly increased in 50 or $100 \mu \mathrm{M}$ PG-treated HPF cells at $24 \mathrm{~h}$ (Fig. 6C). Z-VAD did not alter mitochondrial $\mathrm{O}_{2}{ }^{-}$level in PG-treated HPF cells whereas NAC and vitamin $\mathrm{C}$ decreased the level in these cells (Fig. 6C). BSO increased mitochondrial $\mathrm{O}_{2}^{-}$level in 50 PG-treated HPF cells but it decreased the level in $100 \mu \mathrm{M}$ PG-treated HPF cells (Fig. 6C). When GSH depletion levels in PG-treated HPF cells were assessed in the presence or absence of Z-VAD, NAC, vitamin $\mathrm{C}$ or BSO, only BSO significantly increased GSH depleted cell number in PG-treated HPF cells and the others did not change GSH depletion levels (Fig. 6D).

\section{Discussion}

This study elucidated the cellular effect of PG on cell growth and death in HPF cells in relation to ROS and GSH levels. PG decreased HPF cell growth with an $\mathrm{IC}_{50}$ of $\sim 50-100 \mu \mathrm{M}$. According to previous reports, the $\mathrm{IC}_{50}$ of $\mathrm{PG}$ in Calu- 6 and A549 lung cancer cells was $\sim 20$ and $50 \mu \mathrm{M}$ at $24 \mathrm{~h}$, respectively $(13,15)$. Therefore, the susceptibility to PG in HPF cells was lower than other lung cancer cells. In addition, the growth of calf pulmonary artery endothelial cells is inhibited by PG with an $\mathrm{IC}_{50}$ of $\sim 50 \mu \mathrm{M}$ (23). The difference of susceptibility to PG between these lung cells is probably due to the different basal activities of mitochondria and antioxidant enzymes depending on cell type, tissue origin and species (24). In addition, PG induced a G1 phase arrest of the cell cycle in HPF cells, which might be mediated by the increase of $\mathrm{p} 53$ protein, a CDKI inducer. It is reported that PG induces G1 and G2 phase arrests in A549 (14) and Calu-6 cells (14), respectively. PG also inhibits the growth of As4.1 juxtaglomerular cells via a G2 
phase arrest (25). Alternatively, PG non-specifically induces cell cycle arrests in SNU-484 gastric cancer cells (4) and HeLa cervical cancer cells (2). Taken together, these results suggest that the molecular mechanism of cell cycle arrest by PG has great variety depending on the cell types.

PG induces apoptosis through the downregulation of Bcl-2 protein in cancer cells $(2,25,26)$. Similarly, HPF cell death by $\mathrm{PG}$ was accompanied by a decrease in Bcl-2 protein. In addition, p53 protein, which regulates the expressions of $\mathrm{Bcl}-2$, increased in PG-treated HPF cells. In contrast, Bax level is reported to be upegulated in PG-treated lung cancer cells (26). However, Bax protein in HPF cells was decreased by PG. In addition, Bax level is not changed in PG-treated As4.1 and HeLa cells $(2,25)$. The changes of Bax levels by PG seem to be different depending on cell types. PG-mediated HPF apoptosis probably resulted from the downregulation of $\mathrm{Bcl}-2$ and the upegulation of p53. In addition, PG induces the collapse of MMP $\left(\Delta \Psi_{\mathrm{m}}\right)$ during apoptosis in cancer cells $(4,13-15)$. Correspondingly, PG induced the loss of MMP $\left(\Delta \Psi_{\mathrm{m}}\right)$ in HPF cells and decreased its level in viable HPF cells. The activation of caspase- 3 is important for the process of PG-induced cell death $(2,15,25)$. Likewise, PG apparently increased the activity of caspase- 3 and decreased the precursor form of this caspase. Caspase- 8 is activated in PG-treated Calu-6 lung cells (15). However, the activity of caspase- 8 was not altered in PG-treated HPF cells, implying that PG-mediated HPF apoptosis was not related to receptor- or extrinsic-mediated apoptosis. Its activation by PG can be differently regulated depending on cell types. Interestingly, an increase in sub-G1 cells was not observed in PG-treated HPF cells. Therefore, PG seemed to induce HPF cell death via necrosis as well as apoptosis. In fact, $100 \mu \mathrm{M}$ PG increased the lactate dehydrogenase activity released from HPF cells (unpublished data). In addition, Z-VAD did not affect cell growth inhibition, death and MMP $\left(\Delta \Psi_{\mathrm{m}}\right)$ loss in PG-treated HPF cells. However, Z-VAD including other caspase inhibitors strongly prevented apoptosis in PG-treated cells $(19,23,25)$. It is possible that the mechanism of cell death induced by PG can be different between cancer and normal cells.

ROS level (as determined by DCF) increased in HPF cells treated with 5-50 $\mu \mathrm{M}$ PG, but not $100 \mu \mathrm{M}$ PG at $24 \mathrm{~h}$. However, $100 \mu \mathrm{M}$ PG strongly augmented ROS (DCF) levels at the early time phases of $25-180$ min whereas 10 or $50 \mu \mathrm{M}$ PG did not increase at these times. Because $100 \mu \mathrm{M}$ PG increased CAT protein at $24 \mathrm{~h}$, it is feasible that $\mathrm{ROS}$ such as $\mathrm{H}_{2} \mathrm{O}_{2}$ in $100 \mu \mathrm{M}$ PG-treated HPF cells was rapidly converted into $\mathrm{O}_{2}$ and $\mathrm{H}_{2} \mathrm{O}$ by the increased CAT. In fact, PG increased the activity of CAT in Calu-6 cells and it decreases ROS (DCF) levels (6). $\mathrm{O}_{2}{ }^{--}$level (as determined by DHE) significantly increased in HPF cells treated with 50-100 $\mu \mathrm{M}$, but not 5-20 $\mu \mathrm{M}$ PG. Treatment with $100 \mu \mathrm{M}$ PG transiently increased $\mathrm{O}_{2}{ }^{--}$level at 25 min whereas 10 or $50 \mu \mathrm{M}$ PG decreased the level at this time. At $180 \mathrm{~min}$, all the tested doses of PG increased the $\mathrm{O}_{2}{ }^{--}$levels. Increased $\mathrm{O}_{2}^{--}$levels in PG-treated HPF cells at $24 \mathrm{~h}$ seemed to result from the enhanced production of $\mathrm{O}_{2}{ }^{-}$ itself rather than the reduction of SOD activity since MMP $\left(\Delta \Psi_{\mathrm{m}}\right)$ loss and mitochondrial $\mathrm{O}_{2}{ }^{--}$level increased in these cells and the expression of SOD1 was not downregulated by PG. Especially, PG relatively showed a strong increased effect on mitochondrial $\mathrm{O}_{2}{ }^{--}$level in HPF cells as compared with $\mathrm{O}_{2}{ }^{-}$ level. It is possible that $100 \mu \mathrm{M}$ PG damaged mitochondria and generated $\mathrm{O}_{2}^{-}$level at $25 \mathrm{~min}$, consequently increasing ROS (DCF) levels at the early time phases of 25-180 min. PG did not affect the level of TXNR1 protein in HPF cells but it downregulated TXN level. Because TXN and TXNR1 induce resistance to anticancer drugs (27), the downregulation of TXN by PG may render HPF cells sensitive to this agent.

NAC significantly attenuated $\mathrm{O}_{2}{ }^{\cdot-}$ level including mitochondrial $\mathrm{O}_{2}{ }^{--}$in PG-treated or -untreated HPF cells. It also attenuated cell growth inhibition, cell death and MMP $\left(\Delta \Psi_{\mathrm{m}}\right)$ loss in PG-treated HPF cells. In contrast, BSO strongly enhanced cell growth inhibition, cell death and MMP $\left(\Delta \Psi_{\mathrm{m}}\right)$ loss in PG-treated HPF cells and augmented ROS levels in these cells. In addition, Z-VAD did not significantly alter $\mathrm{O}_{2}{ }^{--}$levels in PG-treated HPF cells. Therefore, PG is likely to induce HPF cell death through oxidative stresses. BSO alone induced cell growth inhibition and cell death in HPF control cells and it strongly increased ROS levels. Therefore, ROS increased by BSO might be related to HPF cell death. Vitamin $\mathrm{C}$ did not prevent cell death and MMP $\left(\Delta \Psi_{\mathrm{m}}\right)$ loss in $50 \mu \mathrm{M}$ PG-treated HPF cells but this agent significantly decreased cell death and MMP $\left(\Delta \Psi_{\mathrm{m}}\right)$ loss by $100 \mu \mathrm{M}$ PG. In addition, vitamin $\mathrm{C}$ increased $\mathrm{O}_{2}^{--}$level in $50 \mu \mathrm{M}$ PG-treated HPF cells whereas it decreased the level in $100 \mu \mathrm{M}$ PG-treated cells. Vitamin $\mathrm{C}$ strongly decreased mitochondrial $\mathrm{O}_{2}{ }^{-}$in 50 or $100 \mu \mathrm{M}$ PG-treated HPF cells. Therefore, vitamin $\mathrm{C}$ showed different effects on cell death in HPF cells depending on the exposed doses of PG. In addition, vitamin $\mathrm{C}$ played a role as a strong antioxidant in reducing mitochondrial $\mathrm{O}_{2}{ }^{--}$level in PG-treated HPF cells.

The intracellular GSH content has a decisive effect on PG-induced apoptosis (4-6,13,23,28). Likewise, PG increased the number of GSH-depleted cells in HPF cells. As expected, $\mathrm{BSO}$ as a GSH synthesis inhibitor increased the numbers of GSH depleted cells in PG-treated HPF cells. In addition, Z-VAD did not change the numbers in these cells. NAC as a GSH precursor attenuates GSH depletion in PG-treated cells $(28,29)$. However, NAC did not affect GSH depletion in PG-treated HPF cells, implying that this agent was not used as a GSH precursor in HPF cells. In addition, vitamin $\mathrm{C}$ did not attenuate GSH depletion in $100 \mu \mathrm{M}$ PG-treated HPF cells and BSO alone did not induce GSH depletion in control HPF cells. These results suggest that an intracellular GSH content is a decisive role in PG-induced HPF cell death but its content change is not enough to estimate cell death precisely.

In conclusion, PG inhibited the growth of HPF cells via the cell death (apoptosis and/or necrosis) as well as a G1 phase arrest of the cell cycle. PG-induced HPF cell death was related to increases in ROS level and GSH depletion. These results provide useful information to understand the cellular effect of PG on normal lung cells in relation to ROS and GSH.

\section{Acknowledgements}

The author would like to thank Dr Bo Ra You for helping with western blot analysis. This study was supported by a grant from the National Research Foundation of Korea (NRF) funded by the Korean government (MSIP; No. 2008-0062279 and 2016R1A2B4007773). 


\section{References}

1. Upadhyay G, Gupta SP, Prakash O and Singh MP: Pyrogallolmediated toxicity and natural antioxidants: Triumphs and pitfalls of preclinical findings and their translational limitations. Chem Biol Interact 183: 333-340, 2010.

2. Kim SW, Han YW, Lee ST, Jeong HJ, Kim SH, Kim IH, Lee SO, Kim DG, Kim SH, Kim SZ, et al: A superoxide anion generator pyrogallol, inhibits the growth of HeLa cells via cell cycle arrest and apoptosis. Mol Carcinog 47: 114-125, 2008.

3. Saeki K, Hayakawa S, Isemura M and Miyase T: Importance of a pyrogallol-type structure in catechin compounds for apoptosisinducing activity. Phytochemistry 53: 391-394, 2000.

4. Park WH, Park MN, Han YH and Kim SW: Pyrogallol inhibits the growth of gastric cancer SNU-484 cells via induction of apoptosis. Int J Mol Med 22: 263-268, 2008.

5. Park WH, Han YW, Kim SH and Kim SZ: A superoxide anion generator, pyrogallol induces apoptosis in As4.1 cells through the depletion of intracellular GSH content. Mutat Res 619: 81-92, 2007.

6. Han YH, Kim SZ, Kim SH and Park WH: Apoptosis in pyrogallol-treated Calu- 6 cells is correlated with the changes of intracellular GSH levels rather than ROS levels. Lung Cancer 59: 301-314, 2008.

7. Gonzalez C, Sanz-Alfayate G, Agapito MT, Gomez-Niño A, Rocher A and Obeso A: Significance of ROS in oxygen sensing in cell systems with sensitivity to physiological hypoxia. Respir Physiol Neurobiol 132: 17-41, 2002.

8. Baran CP, Zeigler MM, Tridandapani S and Marsh CB: The role of ROS and RNS in regulating life and death of blood monocytes. Curr Pharm Des 10: 855-866, 2004.

9. Zorov DB, Juhaszova $M$ and Sollott SJ: Mitochondrial ROS-induced ROS release: An update and review. Biochim Biophys Acta 1757: 509-517, 2006.

10. Zelko IN, Mariani TJ and Folz RJ: Superoxide dismutase multigene family: A comparison of the CuZn-SOD (SOD1), Mn-SOD (SOD2), and EC-SOD (SOD3) gene structures, evolution, and expression. Free Radic Biol Med 33: 337-349, 2002.

11. Wilcox CS: Reactive oxygen species: Roles in blood pressure and kidney function. Curr Hypertens Rep 4: 160-166, 2002.

12. Marks PA: Thioredoxin in cancer - role of histone deacetylase inhibitors. Semin Cancer Biol 16: 436-443, 2006.

13. Han YH, Kim SH, Kim SZ and Park WH: Pyrogallol inhibits the growth of human pulmonary adenocarcinoma A549 cells by arresting cell cycle and triggering apoptosis. J Biochem Mol Toxicol 23: 36-42, 2009.

14. Han YH, Kim SZ, Kim SH and Park WH: Pyrogallol inhibits the growth of human lung cancer Calu-6 cells via arresting the cell cycle arrest. Toxicol In Vitro 22: 1605-1609, 2008.
15. Han YH, Kim SZ, Kim SH and Park WH: Pyrogallol inhibits the growth of lung cancer Calu-6 cells via caspase-dependent apoptosis. Chem Biol Interact 177: 107-114, 2009.

16. Park WH and You BR: Antimycin A induces death of the human pulmonary fibroblast cells via ROS increase and GSH depletion. Int J Oncol 48: 813-820, 2016.

17. You BR, Kim SH and Park WH: Reactive oxygen species, glutathione, and thioredoxin influence suberoyl bishydroxamic acid-induced apoptosis in A549 lung cancer cells. Tumour Biol 36: 3429-3439, 2015.

18. You BR, Shin HR, Han BR and Park WH: PX-12 induces apoptosis in Calu- 6 cells in an oxidative stress-dependent manner. Tumour Biol 36: 2087-2095, 2015.

19. Han YH, Kim SH, Kim SZ and Park WH: Caspase inhibitor decreases apoptosis in pyrogallol-treated lung cancer Calu- 6 cells via the prevention of GSH depletion. Int J Oncol 33: 1099-1105, 2008.

20. Coutts AS and La Thangue N: The p53 response during DNA damage: Impact of transcriptional cofactors. Biochem Soc Symp 73: 181-189, 2006.

21. Porter AG and Jänicke RU: Emerging roles of caspase-3 in apoptosis. Cell Death Differ 6: 99-104, 1999.

22. Ashkenazi A and Dixit VM: Death receptors: Signaling and modulation. Science 281: 1305-1308, 1998.

23. Han YH and Park WH: Pyrogallol-induced calf pulmonary arterial endothelial cell death via caspase-dependent apoptosis and GSH depletion. Food Chem Toxicol 48: 558-563 2010.

24. Oberley LW and Oberley TD: Role of antioxidant enzymes in cell immortalization and transformation. Mol Cell Biochem 84: 147-153, 1988.

25. Park WH, Han YH, Kim SH and Kim SZ: Pyrogallol, ROS generator inhibits As4.1 juxtaglomerular cells via cell cycle arrest of G2 phase and apoptosis. Toxicology 235: 130-139, 2007.

26. Yang CJ, Wang CS, Hung JY, Huang HW, Chia YC, Wang PH, Weng CF and Huang MS: Pyrogallol induces G2-M arrest in human lung cancer cells and inhibits tumor growth in an animal model. Lung Cancer 66: 162-168, 2009.

27. Kim SJ, Miyoshi Y, Taguchi T, Tamaki Y, Nakamura H, Yodoi J, Kato K and Noguchi S: High thioredoxin expression is associated with resistance to docetaxel in primary breast cancer. Clin Cancer Res 11: 8425-8430, 2005.

28. Han YH, Kim SZ, Kim SH and Park WH: Pyrogallol as a glutathione depletor induces apoptosis in HeLa cells. Int J Mol Med 21: 721-730, 2008.

29. Han YH, Moon HJ, You BR, Kim SZ, Kim SH and Park WH: Pyrogallol-induced endothelial cell death is related to GSH depletion rather than ROS level changes. Oncol Rep 23: 287-292, 2010 . 